\title{
Teachers' Perceptions of Online Professional Development in Saudi K-12 Education
}

\author{
Dr. Adam Shami Abdu Al-Amri \\ Al-Qunfudah Educational Directorate, Ministry of Education, Saudi Arabia \\ *E-mail: adamalamri35@gmail.com
}

\begin{abstract}
The current study aimed at exploring teachers' perceptions of online professional development in Saudi K-12 education in relation to the three elements of the $(\mathrm{CoI})$ model: teaching presence, social presence and cognitive presence. The study was carried out at Al-Qunfudah Educational Directorate in the Kingdom of Saudi Arabia. An online questionnaire was distributed to K-12 teachers, and the number of respondents reached (93) male teachers. The results of this study showed that teachers totally agreed on the teaching and cognitive presence of (OPD) activities but their overall responses to the social presence of these activities were uncertain. In light of these results, some recommendations were presented.
\end{abstract}

Keywords: Teachers, Online professional Development, K-12 Education.

DOI: $10.7176 / \mathrm{JEP} / 12-15-03$

Publication date:May $31^{\text {st }} 2021$

\section{Introduction}

Teacher professional development (TPD) helps teachers learn and strengthen their teaching skills. According to (Guskey, 2000), teacher professional development refers to all processes and practices aimed at improving educator's professional knowledge, skills and attitudes in order to enhance students' learning. In the digital age, there is a new concept known as online professional development (OPD), which refers to online activities provided to teachers via the internet and technologies. Because of the social distancing caused by COVID 19, this concept has spread among educators all over the world.

Due to the COVID-19 crisis and the spread of online learning, teachers in Saudi K-12 education faced numerous challenges related to online lesson planning, teaching strategies, and learning assessment techniques. The Kingdom of Saudi Arabia, represented by the Ministry of Education, conducted numerous (OPD) activities to develop K-12 teachers professionally. Regardless of these efforts, recognizing teachers' perceptions of these activities is critical, and it can be viewed as the first step toward their future development.

In the same context, online professional activities must be chosen, guided, and evaluated in accordance with the trends of the guiding models of (OPD). There are many models guiding the activities of (OPD). One of the most widely used models is the community of inquiry (CoI) model (Smith, 2014). This model is used for designing, developing and facilitating teacher online professional development (Elliott, 2017). The (CoI) model consists of three elements including teaching presence, social presence and cognitive presence (Garrison et al., 2000).

Several studies have been conducted in other countries to assess teachers' perceptions of the quality of (OPD) activities (Holmes et al., 2010; Ngeze \& Iyer, 2019; Purnell, 2012; Thomas, 2009), but little is known about teachers' perceptions of these activities in Saudi K-12 education. This study addressed this gap by reporting on teachers' perceptions of (OPD) in Saudi K-12 education in relation to the three elements of the (CoI) model. Understanding teachers' perceptions of (OPD), however, may improve the efficiency and effectiveness of developing better (OPD) activities for teachers in K-12 education, which eventually contribute to better learning outcomes.

As a result, this study came to answer the following three questions: (1) What are teachers' perceptions of the teaching presence of online professional development activities in Saudi K-12 education?, (2) what are teachers' perceptions of the social presence of online professional development activities in Saudi K-12 education? and (3) what are teachers' perceptions of the cognitive presence of online professional development activities in Saudi K-12 education?

\section{Literature Review}

Some studies have focused on online professional development for teachers in K-12 education. Thomas (2009) conducted a study in the context of K-12 education in the United States of America to discover teachers' perceptions of the effectiveness of online professional development courses. The researcher discovered that teachers have positive perceptions of online professional development courses because they can obtain professional development at any time and from any location, despite the presence of certain obstacles such as slow internet connections and a lack of face-to-face interaction.

Another study, conducted in the United States, Boyarko (2009), investigated the elements that teachers 
prefer to be included in the design of online professional development courses at the K-12 level. The author discovered that teachers prefer online professional development content that is relevant to their teaching needs, and this content must be delivered using a variety of presentation techniques.

In the United States, Holmes et al. (2010) conducted a study to investigate teachers' perceptions of online professional development courses in K-12 schools. The authors discovered that teachers strongly agreed that taking these courses improved their skills and teaching methods. The study emphasized the significance of teaching, social, and cognitive presence in online professional development courses.

Purnell (2012) conducted a study in the state of Florida's K-12 public school district to investigate teachers' perceptions of professional development within virtual learning teams. The author discovered that professional development by virtual teams has a positive impact on teachers' social and cognitive levels, as the study revealed an ability for teachers to exchange ideas, gain teaching experience, and learn new technological skills.

Another study on online teacher professional development in K-12 education was conducted in Tanzania (Ngeze \& Iyer, 2019). The researchers discovered that teachers were eager to put new skills to use in their classrooms. According to the findings of the study, online professional development improved teachers' teaching methods, their use of technological resources, and their ability to share their experiences with other teachers in their schools.

Another study conducted in the United States aimed at discovering K-12 teachers' perceptions of (OPD) activities (Parsons et al., 2019). According to the findings of this study, the majority of those teachers had participated in (OPD) activities, and the majority of them found these activities to be either extremely or moderately beneficial.

In light of the foregoing, previous studies have produced varying results regarding teachers' perceptions of (OPD) activities in various K-12 education settings, though little is known about teachers' perceptions of such activities in Saudi K-12 education. As a result, this study focused on teachers' perceptions of these activities in relation to the three elements of the (CoI) model: teaching presence, social presence, and cognitive presence.

\section{Methodology}

This study used a descriptive survey-based approach, which was appropriate for achieving the main goal of this study, which was to investigate teachers' perceptions of (OPD) activities in Saudi K-12 education.

\subsection{Population and Participants}

The target population of this study consisted of all teachers in Al-Qunfudah Educational Directorate in the Kingdom of Saudi Arabia during the school year 2019/2020 and the number of participants in this study reached (93) male teachers who responded to an online questionnaire. Due to the Covid-19 pandemic, those teachers participated in online professional activities organized by Saudi Arabia's Ministry of Education. These activities included online conferences, workshops, and training programs. The table (1) shows the distribution of the participants based on their qualification, teaching grade and the number of teaching years in Saudi K-12 education.

Table 1. Distribution of the participants based on their qualification, teaching grade and the number of teaching years in Saudi K-12 education.

\begin{tabular}{|l|l|l|l|}
\hline & Categories & Frequencies & Percentages \\
\hline Qualification & Bachelor Degree & 88 & 94.6 \\
\cline { 2 - 4 } & Master Degree & 5 & 5.4 \\
\hline \multirow{4}{*}{ Teaching Grade } & Elementary School & 52 & 55.9 \\
\cline { 2 - 4 } & Intermediate School & 28 & 30.1 \\
\cline { 2 - 4 } & Secondary School & 13 & 14.0 \\
\hline \multirow{3}{*}{$\begin{array}{l}\text { Number of Teaching Years } \\
\text { in Saudi K-12 Education }\end{array}$} & 10 years or less & 23 & 24.7 \\
\cline { 2 - 4 } & From 11 to 15 years & 23 & 24.7 \\
\cline { 2 - 4 } & From 16 to 20 years & 24 & 25.8 \\
\cline { 2 - 4 } & More than 20 years & 23 & 24.7 \\
\hline
\end{tabular}

\subsection{Instrument}

To answer the study's questions, the researcher created an online questionnaire based on the educational literature and related previous studies that discussed the three elements of the (CoI) model as one of the most referenced frameworks guiding the processes of online professional development in K-12 education (Sanders \& Lokey-Vega, 2020; Smith, 2014). These elements include the teaching presence, the social presence and the cognitive presence.

In its final form, the questionnaire contained (20) statements distributed across three domains. The first domain included (7) statements about teaching presence, the second domain included (7) statements about social 
presence, and the third domain included (6) statements about cognitive presence. The questionnaire's validity was evaluated using the opinions of experts in the field, and its reliability was determined by calculating the Cronbach alpha coefficient values. The total Cronbach alpha coefficient value is 0.98 , indicating that the questionnaire is highly reliable.

To measure the participants' responses, a five-Likert scale was adopted. The scale ranging from strongly disagree to strongly agree (strongly disagree $=1$, disagree $=2$, uncertain $=3$, agree $=4$, strongly agree $=5$ ) and the following statistical criteria was used to classify the means: $1.00-1.80$ : strongly disagree, $1.81-2.60$ : disagree, 2.61 - 3.40: uncertain, 3.41 - 4.20: agree and 4.21 - 5.00: strongly agree.

\section{Results}

\subsection{Results related to the first question}

Q.1: What are teachers' perceptions of the teaching presence of online professional development activities in Saudi K-12 education?

To answer this question, the researcher calculated means and standard deviations for teachers' responses to the teaching presence of (OPD) activities in Saudi K-12 education. These means and standard deviations are shown in Table (2).

Table (2): Means and standard deviations for measuring teachers' perceptions of the teaching presence of (OPD) activities in Saudi K-12 education

\begin{tabular}{|l|l|l|l|l|l|}
\hline No. & Statement & Mean & Std. & Rank & $\begin{array}{l}\text { Teachers' } \\
\text { Perceptions }\end{array}$ \\
\hline 1 & The objectives of the (OPD) activities are explained. & 3.51 & 1.10 & 4 & Agree \\
\hline 2 & The content of the (OPD) activities is regulated. & 3.53 & 0.96 & 2 & Agree \\
\hline 3 & $\begin{array}{l}\text { There is a connection between the content of the (OPD) } \\
\text { activities and my professional needs. }\end{array}$ & 3.35 & 1.05 & 6 & Uncertain \\
\hline 4 & $\begin{array}{l}\text { There are numerous methods for presenting the content of the } \\
\text { (OPD) activities. }\end{array}$ & 3.57 & 1.02 & 1 & Agree \\
\hline 5 & I can access the content of the (OPD) activities at any time. & 3.41 & 1.03 & 5 & Agree \\
\hline 6 & I can access the content of (OPD) activities from anywhere. & 3.53 & 1.09 & 2 & Agree \\
\hline 7 & $\begin{array}{l}\text { Technical assistance for coping with the (OPD) activities is } \\
\text { available on a continuous basis. }\end{array}$ & 3.25 & 1.06 & 7 & Uncertain \\
\hline & Total & 3.45 & 0.86 & & Agree \\
\hline
\end{tabular}

According to table (2), teachers totally agreed with the statements about the teaching presence of (OPD) activities in Saudi K-12 education, though their responses to statements (3) and (7) were uncertain. It was found that statement (4) is ranked first stated the following: (There are numerous methods for presenting the content of the (OPD) activities) and its mean is 3.57 while statement (7) is ranked last stated the following: (Technical assistance for coping with the (OPD) activities is available on a continuous basis) and its mean is 3.25.

\subsection{Results related to the second question}

Q.2: What are teachers' perceptions of the social presence of online professional development activities in Saudi $\mathrm{K}-12$ education?

To answer this question, the researcher calculated means and standard deviations for teachers' responses to the social presence of (OPD) activities in Saudi K-12 education. These means and standard deviations are shown in Table (3). 
Table (3): Means and standard deviations for measuring teachers' perceptions of the social presence of (OPD) activities in Saudi K-12 education

\begin{tabular}{|l|l|l|l|l|l|}
\hline No. & Statement & Mean & Std. & Rank & $\begin{array}{l}\text { Teachers' } \\
\text { perceptions }\end{array}$ \\
\hline 1 & $\begin{array}{l}\text { There is an opportunity to interact with those who provide } \\
\text { (OPD) activities. }\end{array}$ & 3.33 & 1.03 & 5 & Uncertain \\
\hline 2 & $\begin{array}{l}\text { There is an opportunity to interact with other educators } \\
\text { participating in (OPD) activities. }\end{array}$ & 3.32 & 0.92 & 6 & Uncertain \\
\hline 3 & $\begin{array}{l}\text { There is an opportunity to share my teaching experiences with } \\
\text { those who provide (OPD) activities. }\end{array}$ & 3.26 & 1.00 & 7 & Uncertain \\
\hline 4 & $\begin{array}{l}\text { There is an opportunity to share my teaching experiences with } \\
\text { other teachers participating in (OPD) activities. }\end{array}$ & 3.34 & 0.96 & 4 & Uncertain \\
\hline 5 & $\begin{array}{l}\text { The (OPD) activities have helped the participating teachers } \\
\text { build professional learning communities. }\end{array}$ & 3.40 & 0.99 & 3 & Uncertain \\
\hline 6 & $\begin{array}{l}\text { The (OPD) activities have helped to foster positive } \\
\text { relationships among the teachers who have taken part in them. }\end{array}$ & & 0.96 & 2 & Agree \\
\hline 7 & $\begin{array}{l}\text { The (OPD) activities have helped to create a learning } \\
\text { environment focused on mutual respect among the } \\
\text { participating teachers. }\end{array}$ & 0.95 & 1 & Agree \\
\hline Total & & 3.38 & 0.81 & & Uncertain \\
\hline
\end{tabular}

According to table (3), the teachers' overall responses to statements about the social presence of (OPD) activities in Saudi K-12 education were uncertain, even though they agreed with statements (6) and (7). It was found that statement (7) is ranked first stated the following: (The activities of the (OPD) have helped to create a learning environment focused on mutual respect among the participating teachers) and its mean is 3.62 while statement (3) is ranked last stated the following: (There is an opportunity to share my teaching experiences with those who provide (OPD) activities) and its mean is 3.26 .

\subsection{Results related to the third question}

Q.3: What are teachers' perceptions of the cognitive presence of online professional development activities in Saudi K-12 education?

To answer this question, the researcher calculated means and standard deviations for teachers' responses to the cognitive presence of (OPD) activities in Saudi K-12 education. These means and standard deviations are shown in Table (4).

Table (4): Means and standard deviations for measuring teachers' perceptions of the cognitive presence of (OPD) activities in Saudi K-12 education

\begin{tabular}{|l|l|l|l|l|l|}
\hline No. & Statement & Mean & Std. & Rank & $\begin{array}{l}\text { Teachers' } \\
\text { Perceptions }\end{array}$ \\
\hline 1 & $\begin{array}{l}\text { My involvement in the (OPD) activities helped me gain recent } \\
\text { teaching experience. }\end{array}$ & 3.61 & 1.04 & 5 & Agree \\
\hline 2 & $\begin{array}{l}\text { My involvement in the (OPD) activities allowed me to acquire } \\
\text { a variety of teaching experiences. }\end{array}$ & 3.65 & 1.04 & 4 & Agree \\
\hline 3 & $\begin{array}{l}\text { My involvement in (OPD) activities helped me to improve my } \\
\text { thinking abilities. }\end{array}$ & 3.75 & 1.03 & 1 & Agree \\
\hline 4 & $\begin{array}{l}\text { My involvement in the (OPD) activities helped me learn new } \\
\text { specialized skills. }\end{array}$ & 3.68 & 0.99 & 3 & Agree \\
\hline 5 & $\begin{array}{l}\text { Participating in (OPD) activities enabled me to gain valuable } \\
\text { professional experience. }\end{array}$ & 3.72 & 0.95 & 2 & Agree \\
\hline 6 & $\begin{array}{l}\text { Professional support has been given for the teaching } \\
\text { experience I gained when participating in (OPD) activities. }\end{array}$ & 3.44 & 1.04 & 6 & Agree \\
\hline & Total & 3.64 & 0.94 & & Agree \\
\hline
\end{tabular}

According to table (4), teachers totally agreed with the statements about the cognitive presence of (OPD) activities in Saudi K-12 education. It was found that statement (3) is ranked first stated the following: (My involvement in (OPD) activities helped me to improve my thinking abilities) and its mean is 3.75 while statement (6) is ranked last stated the following: (Professional support has been given for the teaching experience I gained when participating in (OPD) activities) and its mean is 3.44.

\section{Discussion}

The purpose of this study is to discover teachers' perceptions of (OPD) activities in Saudi K-12 education in 
relation to the three elements of the $(\mathrm{CoI})$ model: teaching presence, social presence, and cognitive presence. In general, teachers were found to be in agreement with the teaching and cognitive presence of (OPD) activities in Saudi K-12 education, but their responses to the social presence of these activities were uncertain.

Regarding the results related to the first question of the study, it was discovered that teachers agreed with the statements about the teaching presence of (OPD) activities in Saudi K-12 education. According to the researcher, this result is due to the characteristics of (OPD) activities, which aid in the appropriate presentation of content in a variety of formats, as well as the accessibility of the content at any time and from any location. Previous research on teachers' perceptions of (OPD) activities in K-12 education settings supports this finding (Parsons et al., 2019; Thomas, 2009). According to the findings of these studies, teachers had positive perceptions about the teaching presence of these activities.

As shown in table (2), teachers' responses to statements (3) and (7) regarding the teaching presence of (OPD) in Saudi K-12 education were uncertain. Statement (3) stated the following: There is a connection between the content of the (OPD) activities and my professional needs whereas statement (7) stated the following: Technical assistance for coping with the (OPD) activities is available on a continuous basis. The researcher attributes this result to the (OPD) activities' disadvantages, which include difficulties in meeting the needs of various participants and certain technical difficulties with the internet connection. Teachers prefer that the quality of (OPD) activities be linked to their teaching needs, according to Boyarko (2009). According to Thomas (2009), one of the barriers to (OPD) activities is a poor internet connection. As a result, (OPD) activities must be technologically assisted and tailored to the needs of teachers.

Regarding the results related to the second question of the study, it was discovered that teachers' overall responses to statements about the social presence of (OPD) activities in Saudi K-12 education were uncertain. This finding, according to the researcher, is due to a lack of face-to-face contact among the (OPD) participants. According to Thomas (2009), one of the challenges of (OPD) activities is the lack of face-to-face contact. More efforts are needed to improve the social presence of (OPD) activities in K-12 education.

As shown in table (3), teachers agreed with statements (6) and (7) regarding the social presence of (OPD) in Saudi K-12 education. Statement (6) stated the following: The (OPD) activities have helped to foster positive relationships among the teachers who have taken part in them whereas statement (7) stated the following: The activities of the (OPD) have helped to create a learning environment focused on mutual respect among the participating teachers. This result is supported by the previous study of (Purnell, 2012), which found that (OPD) activities improved teachers' social presence levels.

Regarding the study's third question, it was discovered that teachers totally agreed with the statements related to the cognitive presence of (OPD) activities in Saudi K-12 education. The researcher attributes this to the variety of (OPD) activities introduced in Saudi K-12 education, such as distance learning, teaching methods, online assessment, and online learning platforms. This finding is supported by a previous study by (Purnell, 2012), which discovered that (OPD) activities had a positive impact on the cognitive level of K-12 teachers. Furthermore, Ngeze and Iyer (2019) discovered that (OPD) activities improved teachers' teaching methods as well as their use of technological resources.

\section{Conclusion}

The current study investigated teachers' perceptions of (OPD) activities in Saudi K-12 education in relation to the three elements of the $(\mathrm{CoI})$ model: teaching presence, social presence and cognitive presence. These elements must be introduced, managed, and evaluated in various K-12 settings. According to the current study's findings, teachers in Saudi K-12 education generally agreed on the teaching and cognitive presence of (OPD) activities, but their overall responses to the social presence of these activities were uncertain. As a result, it is recommended that the social presence of (OPD) activities be introduced and studied. Furthermore, teachers' needs in terms of (OPD) activities must be addressed, and more technical assistance must be provided on an ongoing basis.

\section{References}

Boyarko, M. A. (2009). Online professional development: A study of first year online teachers. Doctoral dissertation, Kent State University.

Elliott, J. C. (2017). The evolution from traditional to online professional development: A review. Journal of Digital Learning in Teacher Education, 33(3), 114-125.

Garrison, R., Anderson, T., \& Archer, W. (2000). Critical inquiry in a text-based environment: Computer conferencing in higher education. The Internet and Higher Education, 2(2), 87-105.

Guskey, T. R. (2000). Evaluating professional development. Thousand Oaks, CA: Corwin Press.

Holmes, A., Signer, B., \& MacLeod, A. (2010). Professional development at a distance: A mixed-method study exploring in-service teachers' views on presence online. Journal of Digital Learning in Teacher Education, $27(2), 76-85$ 
Ngeze, L. V., \& Iyer, S. (2019). Online teacher professional development in ICT integration in Tanzania: An experience report. ICCE 2019 - 27th International Conference on Computers in Education, Proceedings, 1, 750-755.

Parsons, S. A., Hutchison, A. C., Hall, L. A., Parsons, A. W., Ives, S. T., \& Leggett, A. B. (2019). U.S. teachers' perceptions of online professional development. Teaching and Teacher Education, 82, 33-42.

Purnell, C. P. (2012). Exploring teachers' perceptions of professional development in virtual learning teams. Doctoral dissertation, Florida Atlantic University.

Sanders, K., \& Lokey-Vega, A. (2020). K-12 community of inquiry: A case study of the applicability of the community of inquiry framework in the K-12 learning environment. Journal of Online Learning Research, $6(1), 35-56$.

Smith, S. U. (2014). Frameworks shaping an online professional development program for K-12 teachers of ELLs: Toward supporting the sharing of ideas for empowering classroom teachers online. TESOL Journal, $5(3), 444-464$.

Thomas, T. scruggs. (2009). Online vs face-to-face: Educator opinions on professional development delivery methods. Doctoral dissertation, The University of Alabama.

Dr. Adam Shami Abdu Al-Amri The author of this paper holds a PhD in the field of curriculum and instruction from King Khalid University (KKU) in Saudi Arabia. He is currently working at Al-Qunfudah Educational Directorate as an educational director. His key interests are teacher professional development, secondary education and educational technology. He has published two books: "Teaching and Learning in Digital Age" and "Teacher's Guide in Professional Knowledge and Practice'. He has presented papers, particularly in the field of education technology, in conferences and journals. 